\title{
Efeito de extratos etanólico de plantas sobre Spodoptera frugiperda (Lepdoptera:
}

\section{Noctuidae)}

\author{
Effect of ethanolic extracts of plants on Spodoptera frugiperda (Lepdoptera: Noctuidae) \\ Efecto de extractos etanólicos de plantas sobre Spodoptera frugiperda (Lepdoptera: Noctuidae)
}

Recebido: 16/01/2022 | Revisado: 21/01/2022 | Aceito: 25/01/2022 | Publicado: 26/01/2022

Janaína De Nadai Corassa

ORCID: https://orcid.org/0000-0002-1013-5414 Universidade Federal de Mato Grosso, Brasil

E-mail: janadenadai@gmail.com

Monique Machiner

ORCID: https://orcid.org/0000-0003-0838-8639 Universidade Federal de Mato Grosso, Brasil E-mail: machinermonique@gmail.com

Dênia Mendes de Sousa Valladao

ORCID: https://orcid.org/0000-0002-2643-1963 Universidade Federal de Mato Grosso, Brasil E-mail: deniavalladao@gmail.com

Carla Regina Andrighetti

ORCID: https://orcid.org/0000-0001-6307-8399 Universidade Federal de Mato Grosso, Brasil E-mail: deniavalladao@gmail.com Jaqueline Bilenki Weberling

ORCID: https://orcid.org/0000-0000-0000-0000 Universidade Federal de Mato Grosso, Brasil E-mail: bilenkijaqueline@gmail.com

\begin{abstract}
Resumo
A lagarta Spodoptera frugiperda representa um grande problema na cultura do milho e o uso de inseticida é a medida de controle mais utilizada. Os principais problemas relacionados com essa prática dizem respeito ao desenvolvimento de linhagens resistentes de lagartas. Estudos de plantas com propriedades inseticidas para o controle desta praga têm crescido, devido aos menores impactos do seu uso. O objetivo do trabalho foi avaliar em laboratório o potencial inseticida das folhas das plantas Chrysanthemum morifolium (Asterales: Asteraceae), Dieffenbachia picta (Alismatales: Araceae), Sansevieira trifasciata (Asparagales: Asparagaceae) e Tagetes erecta (Asterales: Asteraceae) sobre a mortalidade de lagartas Spodoptera frugiperda. As lagartas foram criadas em laboratório, e mantidas sob dieta artificial. Para os bioensaios com plantas foram utilizados lagartas de terceiro ínstar em dois métodos, controle e ingestão. O período de avaliação foi de cinco dias. Foram considerados mortos os indivíduos que quando tocado com a ponta de um pincel nos últimos segmentos abdominais não respondeu com movimentos coordenados. Todas as quatro plantas avaliadas $C$. morifolium, D. picta, S. trifasciata e T. erecta acarretaram a morte de um baixo número de lagartas $S$. frugiperda. As plantas $C$. morifolium e $S$. trifasciata apesar da baixa mortalidade foram as que se destacaram com respectivamente 13,19\% e 12,49\% lagartas mortas na concentração de $70 \%$ ao fim das avaliações. O método de ação variou entre as duas plantas sendo que para o C. morifolium o método de contato e ingestão foram estatisticamente iguais a partir do terceiro dia enquanto para a $S$. trifasciata o método de contato foi melhor e acarretou a morte de mais lagartas. Conclui-se que apesar da baixa mortalidade com os extratos, as plantas $C$. morifolium e $S$. trifasciata apresentaram maior mortalidade que as demais. O extrato é obtido de maneira bruta, tendo sua eficiência mínima avaliada.
\end{abstract}

Palavras-chave: Contato; Ingestão; Lagarta-do-cartucho; Milho; Plantas inseticidas; Pragas.

\begin{abstract}
Spodoptera frugiperda worm represents a major problem in maize crop and the use of insecticide is the most used control measure. The main problems related to this practice are related to the development of resistant worm lineages. Studies of plants with insecticidal properties to control this pest have grown due to the lower impacts of their use. The objective of this study was to evaluate the insecticidal potential of the plants Chrysanthemum morifolium (Asterales: Asteraceae), Dieffenbachia picta (Alismatales: Araceae), Sansevieira trifasciata (Asparagales: Asparagaceae) and Tagetes erecta (Asterales: Asteraceae) on Spodoptera frugiperda worm mortality. The worms were raised in the laboratory, and kept under artificial diet. For the plant bioassays third instar larvae were used in two methods, control contat and ingestion. The evaluation period was five days. Individuals who when touched with the tip of a brush in the
\end{abstract}


last abdominal segments did not respond with coordinated movements were considered dead. All four evaluated plants C. morifolium, D. picta, S. trifasciata and T. erecta caused the death of a low number of S. frugiperda worms. The $C$. morifolium and $S$. trifasciata plants, despite the low mortality rate, were those that stood out with $13.19 \%$ and $12.49 \%$ dead worms at the $70 \%$ concentration at the end of the evaluations. The method of action varied between the two plants and for $C$. morifolium the method of contact and ingestion were statistically the same from day three while for $S$. trifasciata the method of contact was better and resulted in the death of more caterpillars. It is concluded that in spite of the low mortality with the extracts, the plants $C$. morifolium and $S$. trifasciata presented higher mortality than the others. Note that the extract is obtained in a crude way, having its minimum efficiency evaluated.

Keywords: Armyworm; Contact; Ingestion; Insecticidal plants; Maize; Pests.

\section{Resumen}

La oruga Spodoptera frugiperda representa un gran problema en el cultivo del maíz y el uso de insecticidas es la medida de control más utilizada. Los principales problemas relacionados con esta práctica están relacionados con el desarrollo de cepas resistentes de orugas. Han crecido los estudios de plantas con propiedades insecticidas para el control de esta plaga, debido a los menores impactos de su uso. El objetivo de este trabajo fue evaluar en laboratorio el potencial insecticida de plantas de Chrysanthemum morifolium (Asterales: Asteraceae), Dieffenbachia picta (Alismatales: Araceae), Sansevieira trifasciata (Asparagales: Asparagaceae) y Tagetes erecta (Asterales: Asteraceae) sobre la mortalidad de orugas. Las orugas se criaron en el laboratorio y se mantuvieron con una dieta artificial. Para los bioensayos de plantas, se utilizaron orugas de tercer estadio en dos métodos, control e ingestión. El período de evaluación fue de cinco días. Los individuos que, al ser tocados con la punta de un cepillo en los últimos segmentos abdominales, no respondieron con movimientos coordinados, fueron considerados muertos. Las cuatro plantas evaluadas, C. morifolium, D. picta, S. trifasciata y $T$. erecta provocaron la muerte de un número bajo de orugas de $S$. frugiperda. Las plantas C. morifolium y S. trifasciata, a pesar de la baja mortalidad, se destacaron con $13,19 \%$ y $12,49 \%$ de orugas muertas respectivamente a una concentración del $70 \%$ al final de las evaluaciones. El método de acción varió entre las dos plantas y para $C$. morifolium los métodos de contacto e ingestión fueron estadísticamente iguales desde el tercer día en adelante, mientras que para $S$. trifasciata el método de contacto fue mejor y resultó en la muerte de más orugas. Se concluye que a pesar de la baja mortalidad con los extractos, las plantas C. morifolium y $S$. trifasciata presentaron mayor mortalidad que las demás. El extracto se obtiene de forma cruda, habiendo evaluado su eficiencia mínima.

Palabras clave: Contacto; Ingestión; Gusano cogollero; Maíz; Plantas insecticidas; Plagas.

\section{Introdução}

O cultivo do milho é realizado em todos os estados do Brasil, entretanto, as regiões sul, centro oeste e sudeste concentram a maior parte da produção. Os Estados do Paraná, Mato Grosso e Rio Grande do Sul são responsáveis por mais da metade do milho produzido no Brasil (Caldarelli e Bacchi, 2012). No entanto, existem fatores que limitam a produtividade dessa cultura no Brasil (Zanon et al., 2015), entre eles, podemos destacar as lagartas.

A lagarta Spodoptera frugiperda conhecida popularmente como lagarta-do-cartucho é umas das principais preocupações no cultivo do milho. A praga é muito voraz e pode ser encontrada em todos os estádios e órgãos da planta. Seu controle é realizado na grande maioria com inseticidas químicos e espécies transgênicas. Entretanto, uso inadequado e aplicações excessivas realizadas em momentos impróprios acarretam em problemas ambientais e no surgimento de população resistente (Barcelos et al., 2013).

A ocorrência de elevadas densidades populacionais de insetos-pragas, a resistência comprovada de populações das pragas a alguns inseticidas, as falhas de controle e o desequilíbrio ambiental são fatores que potencializam o ataque desses insetos, causando sérios danos a cultura, tornando o seu manejo cada vez mais desafiador para o agricultor (Bueno et al., 2012; Guedes et al., 2012).

A contínua aplicação de inseticidas mantém a lagarta $S$. frugiperda em permanente pressão de seleção, diminuindo assim a eficiência e a viabilidade dos principais grupos químicos como piretróides, organofosforados, carbamatos, benzoilureias e espinosinas. Esse consumo exacerbado se contrapõe a teoria do MIP, afinal não só os organismos benéficos são comprometidos, o ambiente é prejudicado num todo, arriscando até a saúde humana (Barcelos et al., 2013).

A busca por novos meios de controle da lagarta $S$. frugiperda fez com que surgissem novas tecnologias, como as plantas de milho geneticamente modificadas. O uso do milho transgênico contribuiu para a redução do uso de inseticidas 
químicos, permitindo desta forma uma produção mais sustentável. Entretanto, assim como os inseticidas, o uso incorreto acarreta em populações de insetos pragas resistentes (Carvalho et al., 2013).

A busca por alternativas de controle sustentáveis para a lagarta S. frugiperda, que diminuam os riscos ao ambiente e aos organismos benéficos, estão crescendo no cenário científico. Pesquisas utilizando extratos vegetais estão ganhando espaço. Produtos a partir de vegetais podem vir a diminuir problemas ambientais e saúde pública por serem renováveis e degradáveis, além de reduzir problemas com populações resistentes, devido ao fato dos insetos desenvolvem resistência de maneira mais lenta a estas substâncias (Resende et al., 2014).

Considerando o avanço nas pesquisas relacionadas aos inseticidas de origem botânica e as perspectivas para a sua utilização no controle de insetos praga, desenvolveu-se este trabalho com o objetivo de avaliar, em condições de laboratório, o efeito inseticida do extrato aquoso de Chrysanthemum morifolium (Asterales: Asteraceae), Dieffenbachia picta (Alismatales: Araceae), Sansevieira trifasciata (Asparagales: Asparagaceae) e Tagetes erecta (Asterales: Asteraceae) sobre lagartas de Spodoptera frugiperda (Lepdoptera: Noctuidae).

\section{Metodologia}

A pesquisa é de natureza quantitativa e qualitativa e foi desenvolvida em laboratório.

Foram coletadas amostras de 180 lagartas $S$. frugiperda, as lagartas foram criadas em laboratório, e mantidas sob dieta artificial. Foram utilizadas lagartas de terceiro ínstar em dois métodos, controle e ingestão. O período de avaliação foi de cinco dias. Foram considerados mortos os indivíduos que quando tocado com a ponta de um pincel nos últimos segmentos abdominais não respondeu com movimentos coordenados.

\subsection{Coleta e criação de Spodoptera frugiperda}

Uma população de lagarta da espécie S. frugiperda foi coletada em área de produção de milho localizada no município de Sinop-MT (Latitude: -1151'24,12”; Longitude: -55²7’33,48”), na safra 17/18.

Durante a coleta 180 lagartas S. frugiperda foram colocadas em potes plásticos transparentes de $10 \mathrm{~mL}$ contendo 5 $\mathrm{mL}$ de dieta artificial a base de feijão branco (Parra, 2001) e mantidas em caixas térmicas. Ao chegarem ao laboratório os potes plásticos contendo as lagartas $S$. frugiperda foram alocados em estantes e mantidos a temperatura ambiente de $\pm 25^{\circ} \mathrm{C}$ até se transformarem em pupa.

Após a emergência dos adultos, cerca de 20 casais foram transferidos para cada gaiola de tubo de PVC (cloreto de polivinila) de $30 \mathrm{~cm}$ de diâmetro por $30 \mathrm{~cm}$ de altura, revestidas internamente com folhas de papel sulfite e recobertas com voal.

Para a alimentação dos adultos utilizou-se potes plásticos com algodão embebido em solução de mel a 10\% no interior das gaiolas. Os adultos foram mantidos em sala de criação à temperatura de $\pm 25^{\circ} \mathrm{C}$. A cada dois dias o revestimento interno de papel sulfite das gaiolas e os potes plásticos contendo alimento para os adultos eram trocados.

As posturas contidas no papel sulfite foram recortadas e colocadas em vasilhas plásticas transparentes (Plasmont 3,6 L) contendo cubos de dieta artificial e mantidas em câmara incubadora com temperatura regulada para $\pm 25^{\circ} \mathrm{C}$, fotofase de 12 horas e umidade de $\pm 60 \%$ até o momento da eclosão dos neonatos.

Os neonatos de duas populações foram divididos em dois lotes, sendo um destinado para a manutenção da população de lagartas $S$. frugiperda, e o outro para a realização dos bioensaios com os extratos aquosos extraídos das plantas Chrysanthemum morifolium, Dieffenbachia picta, Sansevieira trifasciata e Tagetes erecta. 


\subsection{Coleta dos materiais e obtenção dos extratos}

As folhas das plantas Chrysanthemum morifolium (Asterales: Asteraceae), Dieffenbachia picta (Alismatales: Araceae), Sansevieira trifasciata (Asparagales: Asparagaceae) e Tagetes erecta (Asterales: Asteraceae) foram coletadas em diferentes locais localizados dentro do município de Sinop-MT. Posteriormente a coleta, o material vegetal foi armazenado em sacos de papel e mantido congelado até o momento da produção dos extratos. Os extratos foram obtidos a partir da parte aérea fresca das plantas (caule, folhas e flores).

Para a obtenção do extrato aquoso, 20g de material vegetal das plantas Chrysanthemum morifolium, Dieffenbachia picta, Sansevieira trifasciata e Tagetes erecta foi picotado manualmente em pedaços de aproximadamente $2,0 \mathrm{~cm}$. Posteriormente o material vegetal foi submetido à lavagem em solução de hipoclorito de sódio $(1 \mathrm{~mL})$ com água destilada (50 $\mathrm{mL}$ ) durante cinco minutos, para reduzir a possibilidade de contaminação com fungos e bactérias. Com o material vegetal limpo triturou-se em liquidificador ( 3 ciclos de 15 segundos cada), com $40 \mathrm{~mL}$ de água destilada a temperatura de $50{ }^{\circ} \mathrm{C}$.

Após o processo de trituração, a mistura foi depositada em Becker de vidro coberto com papel alumínio, permanecendo em repouso sob condições de temperatura e ambiente e protegida da luz por uma hora. Após a infusão a mistura foi filtrada em funil de Buncher, contendo uma camada de gaze, resultando assim no extrato bruto (extrato aquoso a $100 \%$ $50 \%$ p/v) (Simões et al., 2016).

Para avaliação desses extratos sobre a mortalidade das lagartas S. frugiperda, os mesmos foram diluídos nas seguintes concentrações:
C1: Extrato aquoso a $50 \%-(25 \% \mathrm{p} / \mathrm{v})$;
C2: Extrato aquoso a $60 \%$ - $(30 \% \mathrm{p} / \mathrm{v})$;
C3: Extrato aquoso a $70 \%-(35 \% \mathrm{p} / \mathrm{v})$.

\subsection{Bioensaios}

Utilizou-se bioensaios de ingestão e contato para os extratos das plantas chrysanthemum morifolium ramat, dieffenbachia picta schott, sansevieira trifasciata prain e tagetes erecta 1. Para a realização dos bioensaios placas de elisa plásticas (prolab), contendo 24 células foram preenchidas individualmente com 1,5 $\mathrm{ml}$ de dieta artificial, mantidas em câmera de fluxo laminar até a geleificação da dieta.

Os bioensaios de ingestão foram realizados mediante o tratamento superficial da dieta artificial com $30 \mu \mathrm{L}$ dos extratos aquosos das plantas em cada célula da placa plástica, as mesmas eram mantidas em câmera de fluxo laminar para absorção e secagem completa. Após, uma lagarta S. frugiperda de $3^{\circ}$ ínstar foi transferida para cada célula da placa plástica com o auxílio de um pincel. Nos bioensaios de contato, lagartas S. frugiperda de $3^{\circ}$ ínstar foram adicionadas individualmente, com o auxílio de um pincel, em cada célula da placa plástica e posteriormente $5 \mu \mathrm{L}$ dos extratos aquosos das plantas foram pipetados sobre o dorso das mesmas.

Como controle positivo, em ambos os métodos de ingestão e contato foi utilizado o inseticida Pirate $($ BASF), que possui como princípio ativo o Clorfenapir seguindo as instruções de uso contidas na bula do produto para a cultura e praga. No controle negativo utilizou-se apenas água destilada.

Para cada bioensaio foram utilizadas 3 repetições, sendo que cada uma era constituída de 24 lagartas e 3 tratamentos (Concentrações: 50\%, 60\% e 70\%). As placas com os bioensaios foram mantidas em sala de criação climatizada, com temperatura controlada de $\pm 25^{\circ} \mathrm{C}$ (Gallo et al., 2002). As mortalidades foram avaliadas $24,48,72,96$ e 120 horas após a instalação do bioensaio. Foi considerado morto o indivíduo que ao ser tocado com a ponta de um pincel nos últimos segmentos abdominais não respondeu com movimentos coordenados. 


\subsection{Análises estatísticas}

O delineamento experimental adotado nos experimentos de avaliação de mortalidade da lagarta S. frugiperda foi o inteiramente casualizado no esquema de parcelas subdivididas no tempo, com fatorial na parcela. Os fatores das parcelas são as concentrações $(50 \%, 60 \%$ 70\%) e as ações (ingestão e contato) avaliadas ao longo de cinco dias. Os dados foram submetidos à análise de variância e as médias foram comparadas entre si, por meio da aplicação do teste de Scott Knott ao nível de 5\% de probabilidade, utilizando-se para as análises o programa estatístico SISVAR® (Ferreira, 2011)

\section{Resultados e Discussão}

\subsection{Chrysanthemum morifolium}

De acordo com a análise estatística observou-se que não houve diferença significativa entre as concentrações de extrato de C. morifolium testadas para ambos os métodos de ação, ingestão e contato.

Em ambos os métodos de ação o controle positivo diferiu estatisticamente das demais concentrações testadas, apresentando $100 \%$ das lagartas mortas e as concentrações de 50\%, 60\% e 70\%, não diferiram do controle negativo. Para o método de ingestão segue a ordem decrescente de mortalidade das concentrações de $70 \%>50 \%>60 \%$, enquanto para o método de contato foi de $70 \%>60 \%>50 \%$.

A avaliação da mortalidade das lagartas $S$. frugiperda com a aplicação do extrato aquoso de C. morifolium nas concentrações de 50\%, 60\% e 70\% não apresentaram diferença significativa em nenhum dos métodos de ação utilizados (Tabela 1).

Tabela 1. Porcentagem de mortalidade de $S$. frugiperda após a aplicação das concentrações do extrato aquoso de $C$. morifolium pelos métodos de ação de ingestão e contato.

\begin{tabular}{ccc}
\hline & \multicolumn{2}{c}{ Ação } \\
Concentrações & Ingestão & Contato \\
\hline $50 \%$ & $6,11 \mathrm{bA}$ & $3,61 \mathrm{bA}$ \\
$60 \%$ & $2,50 \mathrm{bA}$ & $3,89 \mathrm{bA}$ \\
$70 \%$ & $7,50 \mathrm{bA}$ & $9,17 \mathrm{bA}$ \\
Controle positivo & $100 \mathrm{aA}$ & $100 \mathrm{aA}$ \\
Controle negativo & $0 \mathrm{bA}$ & $0 \mathrm{bA}$ \\
CV $(\%)$ & & 35,26 \\
\hline
\end{tabular}

Médias seguidas de mesma letra minúscula nas colunas e maiúsculas nas linhas não diferem entre si pelo teste de Scott knott ao nível de 5\% de probabilidade. Fonte: Autores.

Em relação aos dias de avaliação o controle positivo foi superior, levando $100 \%$ das lagartas à morte ainda no primeiro dia. Enquanto o controle negativo não apresentou nenhuma lagarta morta durante o período de avaliação. No primeiro dia as concentrações de 50\%,60\% e 70\% foram estatisticamente iguais pelo teste de Scott Knott, apresentando baixas taxas de mortalidade, de 0,1 e 2 lagartas mortas respectivamente. Já no segundo dia observou-se que a concentração de $60 \%$ foi inferior as demais, mantendo seu desempenho estatisticamente igual ao controle negativo. As demais concentrações de 50\% e $70 \%$ ocasionaram a morte de 7 e 9 lagartas, e foram consideradas semelhantes pelo teste estatístico (Tabela 2).

A partir do terceiro dia a concentração de $70 \%$ foi superior as demais nas avaliações posteriores, no último dia de avaliação havia um total 19 lagartas mortas. Ainda no terceiro dia foi possível avaliar que as concentrações de 50\% e 60\% não diferiram entre si. No quarto dia houve um acréscimo da mortalidade na concentração de 50\%, chegando a 10 lagartas mortas.

As três concentrações avaliadas se mostraram mais eficazes a partir do terceiro dia após a aplicação do extrato. Os valores mais significativos foram observados na concentração de 70\% que no quinto dia possuía 19 lagartas mortas (Tabela 2). 
Tabela 2. Médias de mortalidade de lagartas $S$. frugiperda avaliadas por cinco dias após a aplicação do extrato de $C$. morifolium nas concentrações testadas.

\begin{tabular}{|c|c|c|c|c|c|}
\hline \multirow{2}{*}{ Concentrações } & \multicolumn{5}{|c|}{ Dias } \\
\hline & 1 & 2 & 3 & 4 & 5 \\
\hline $50 \%$ & ObB & $4,86 \mathrm{bA}$ & $5,55 \mathrm{cA}$ & $6,94 \mathrm{cA}$ & $6,94 \mathrm{cA}$ \\
\hline $60 \%$ & $0,69 \mathrm{bB}$ & $1,39 \mathrm{cB}$ & $4,17 \mathrm{cA}$ & $4,17 \mathrm{dA}$ & $5,55 \mathrm{cA}$ \\
\hline $70 \%$ & $1,38 \mathrm{bC}$ & $6,25 \mathrm{bB}$ & $9,72 \mathrm{bA}$ & $11,11 \mathrm{bA}$ & $13,19 \mathrm{bA}$ \\
\hline Controle positivo & $100 \mathrm{aA}$ & $100 \mathrm{aA}$ & $100 \mathrm{aA}$ & $100 \mathrm{aA}$ & $100 \mathrm{aA}$ \\
\hline Controle negativo & $0 \mathrm{bA}$ & $0 \mathrm{cA}$ & $0 \mathrm{dA}$ & $0 \mathrm{eA}$ & OdA \\
\hline $\mathrm{CV}(\%)$ & \multicolumn{5}{|c|}{12,72} \\
\hline
\end{tabular}

Médias seguidas de mesma letra minúscula nas colunas e maiúsculas nas linhas não diferem entre si pelo teste de Scott knott ao nível de 5\% de probabilidade. Fonte: Autores.

Foi possível observar que não houve diferenças significativas entre os métodos de ação utilizados, ou seja, em cada um dos dias avaliados a taxa de mortalidade foi semelhante para ambos os métodos. Os métodos de ação ingestão e contato apresentaram maiores taxas de mortalidade na ordem decrescente de dias de $5^{\circ}>4^{\circ}>3^{\circ}$ (Tabela 3 ).

Tabela 3. Avaliação da mortalidade de lagartas $S$. frugiperda nos métodos de ação ingestão e contato utilizados na aplicação do extrato de C. morifolium durante os cinco dias de avaliação.

\section{Dias}

\begin{tabular}{cccccc} 
Concentrações & \multicolumn{5}{c}{ - } \\
& 1 & 2 & 3 & 4 & 5 \\
\hline Ingestão & $20,55 \mathrm{aB}$ & $22,50 \mathrm{aB}$ & $23,88 \mathrm{aA}$ & $24,44 \mathrm{aA}$ & $24,72 \mathrm{aA}$ \\
Contato & $20,28 \mathrm{aC}$ & $22,50 \mathrm{aB}$ & $23,88 \mathrm{aA}$ & $24,44 \mathrm{aA}$ & $25,55 \mathrm{aA}$ \\
CV $(\%)$ & \multicolumn{5}{c}{12,72} \\
\hline
\end{tabular}

Médias seguidas de mesma letra minúscula nas colunas e maiúsculas nas linhas não diferem entre si pelo teste de Scott knott ao nível de 5\% de probabilidade. Fonte: Autores.

Mazzoneto e colaboradores (2013) relatam que após o tratamento de discos de folha de milho com o extrato da espécie Chrysanthemum leucanthemum (Asterales: Asteraceae) foi possível observar efeito fago deterrente sobre a lagarta $S$. frugiperda, ou seja, reduz a capacidade de alimentação da mesma e consequentemente os danos ocasionados as plantas. Os mesmos autores também descrevem que o extrato aquoso de $C$. leucanthemum não apresentou efeito ovicida para a lagarta.

Estudos relatam que o extrato de Chrysanthemum cinerariaefolium (Asterales: Asteraceae) apresentou efeito positivo no controle de Tribolium castaneum (Herbest, 1797) (Coleptera: Tenebrionidae) em arroz armazenado, levando a morte um significativo número de insetos. O autor enfatiza a importância de novas pesquisas, utilizando diferentes doses e diferentes metodologias, visando avaliar a eficiência do extrato em outras condições (Silva et al., 2015).

Na literatura não há relatos do uso da espécie $C$. morifolium no controle de insetos pragas. Suas funções medicinais para desintoxicar o sangue, regular a pressão, tratar infecções bacterianas e virais, problemas digestivos, câncer do cólon e potencial anti-HIV são conhecidas e bastante pesquisadas a fim de aprimorar o conhecimento dos compostos presentes nesta espécie (Yeasmin et al., 2016).

\subsection{Dieffenbachia picta}

A espécie D. picta não apresentou diferença estatística entre as concentrações para nenhum dos métodos de ação avaliados. Para ambos os métodos as concentrações foram estatisticamente iguais ao controle negativo, possuindo baixa taxa 
de mortalidade. O controle positivo matou $100 \%$ das lagartas tanto no método de ingestão quanto no método de contato (Tabela 4).

As concentrações $60 \%, 70 \%$, controle positivo e controle negativo apresentaram taxas de lagartas mortas semelhantes entre os métodos de ação não diferindo entre si pelo teste estatístico de Scott Knott. A concentração de 50\% diferiu em número de lagartas mortas entre os métodos, apresentando 2 lagartas mortas no método de ingestão e 12 lagartas mortas no método de contato.

Tabela 4. Porcentagem de mortalidade de S. frugiperda após a aplicação das concentrações do extrato aquoso de D. picta pelos métodos de ação de ingestão e contato.

\begin{tabular}{ccc}
\hline & & Ação \\
Concentrações & Ingestão & Contato \\
\hline $50 \%$ & $1,38 \mathrm{bB}$ & $8,61 \mathrm{bA}$ \\
$60 \%$ & $0,83 \mathrm{bA}$ & $5,55 \mathrm{bA}$ \\
$70 \%$ & $3,89 \mathrm{bA}$ & $7,22 \mathrm{bA}$ \\
Controle positivo & $100 \mathrm{aA}$ & $100 \mathrm{aA}$ \\
Controle negativo & $0 \mathrm{bA}$ & $0 \mathrm{bA}$ \\
$\mathrm{CV}(\%)$ & & 40,59 \\
\hline
\end{tabular}

Médias seguidas de mesma letra minúscula nas colunas e maiúsculas nas linhas não diferem entre si pelo teste de Scott knott ao nível de 5\% de probabilidade. Fonte: Autores.

No primeiro dia de avaliação o controle positivo havia matado $100 \%$ das lagartas, mostrando sua eficácia no controle da lagarta. O controle negativo diferiu de todas as demais concentrações no decorrer de cada dia avaliado, sendo que no quinto dia todas as lagartas ainda permaneciam vivas (Tabela 5).

No primeiro dia de avaliação as três concentrações foram semelhantes pelo teste estatístico, ocasionando a mortalidade de 5 lagartas na concentração de $50 \%$ e 4 lagartas nas concentrações de $60 \%$ e $70 \%$. No segundo dia a concentração de $70 \%$ foi superior as demais com 7 lagartas mortas. A partir do terceiro dia as concentrações de 50\% e 70\% foram superiores, chegando ao quinto dia com respectivamente 8 e 9 lagartas mortas. A concentração de $60 \%$ após o segundo dia estagnou com 5 lagartas mortas, permanecendo assim até o fim das avaliações.

Para as concentrações de 50\% e 70\% é possível observarmos que a partir do terceiro dia houve aumento nas médias de mortalidade de lagartas $S$. frugiperda possuindo ao quinto dia de avaliação respectivamente 9 e 10 lagartas mortas. A concentração de $60 \%$ foi a que apresentou o pior desempenho durante os cinco dias. A concentração de 50\% apresentou maior número de lagartas mortas nos $3^{\circ}, 4^{\circ}$ e $5^{\circ}$ dias, sseguidos pelos $1^{\circ}$ e $2^{\circ}$ dia. Já para a concentração de $60 \%$ não houve diferença estatística para a mortalidade de lagartas S. frugiperda entre os dias avaliados. Enquanto que a concentração de $70 \%$ foi semelhante a de $50 \%$ sendo os $3^{\circ}, 4^{\circ}$ e $5^{\circ}$ dia os com as maiores taxas de mortalidade, seguindos pedo $2^{\circ}$ e posteriormente pelo $3^{\circ}$. 
Tabela 5. Médias de mortalidade de lagartas $S$. frugiperda avaliadas por cinco dias após a aplicação do extrato de D. picta nas concentrações testadas.

\begin{tabular}{cccccc}
\hline & & \multicolumn{5}{c}{ Dias } \\
Concentrações & 1 & 2 & 3 & 4 & 5 \\
\hline $50 \%$ & $3,37 \mathrm{bB}$ & $3,47 \mathrm{cB}$ & $5,55 \mathrm{bA}$ & $6,25 \mathrm{bA}$ & $6,25 \mathrm{bA}$ \\
$60 \%$ & $2,77 \mathrm{bA}$ & $2,77 \mathrm{cA}$ & $3,47 \mathrm{cA}$ & $3,47 \mathrm{cA}$ & $3,47 \mathrm{cA}$ \\
$70 \%$ & $2,77 \mathrm{bC}$ & $4,86 \mathrm{bB}$ & $6,25 \mathrm{bA}$ & $6,94 \mathrm{bA}$ & $6,94 \mathrm{bA}$ \\
Controle positivo & $100 \mathrm{aA}$ & $100 \mathrm{aA}$ & $100 \mathrm{aA}$ & $100 \mathrm{aA}$ & $100 \mathrm{aA}$ \\
Controle negativo & $0 \mathrm{cA}$ & $0 \mathrm{dA}$ & $0 \mathrm{dA}$ & $0 \mathrm{dA}$ & $0 \mathrm{dA}$ \\
CV (\%) & & & & 4,61 & \\
\hline
\end{tabular}

Médias seguidas de mesma letra minúscula nas colunas e maiúsculas nas linhas não diferem entre si pelo teste de Scott knott ao nível de 5\% de probabilidade. Fonte: Autores.

Durante os cinco dias de avaliação o método de ação por contato foi superior, possuindo $5^{\circ}$ dia 44 lagartas mortas enquanto o método de ingestão. Avaliando os métodos individualmente é possível afirmar que ambos tiveram suas médias aumentadas a partir do terceiro dia (Tabela 6).

Tabela 6. Avaliação da mortalidade de lagartas S. frugiperda nos métodos de ação ingestão e contato utilizados na aplicação do extrato de D. picta durante os cinco dias de avaliação.

\begin{tabular}{|c|c|c|c|c|c|}
\hline \multirow{3}{*}{ Concentrações } & \multicolumn{5}{|c|}{ Dias } \\
\hline & & -------------- & ---------Mo & (\%)--------- & \\
\hline & 1 & 2 & 3 & 4 & 5 \\
\hline Ingestão & $20,55 \mathrm{bB}$ & $20,83 \mathrm{bB}$ & $21,39 \mathrm{bA}$ & $21,66 \mathrm{bA}$ & $21,67 \mathrm{bA}$ \\
\hline Contato & $23,05 \mathrm{aB}$ & $23,61 \mathrm{aB}$ & $24,72 \mathrm{aA}$ & $24,99 \mathrm{aA}$ & $24,99 \mathrm{aA}$ \\
\hline $\mathrm{CV}(\%)$ & & & & & \\
\hline
\end{tabular}

Médias seguidas de mesma letra minúscula nas colunas e maiúsculas nas linhas não diferem entre si pelo teste de Scott knott ao nível de 5\% de probabilidade. Fonte: Autores.

$\mathrm{Na}$ literatura científica não há trabalhos relatando os efeitos do extrato aquoso de D. picta no controle de insetos, existindo apenas pesquisas descrevendo seu efeito tóxico sobre humanos e animais. Loretti e colaboradores (2003) relataram que após o consumo moderado da planta cães conseguem se recuperar sem intercorrências, e que a morte ocasionada por asfixia do cão é extremamente raro. O consumo de espécies de Dieffenbachia com elevada quantidade de seiva levam ao inchaço edematoso grave da glote com oclusão da passagem da via aérea da laringe.

Segundo Altin e colaboradores (2013) a toxidade das plantas de Dieffenbachia pode ser fatal, entretanto são raros. Sua mastigação pode ocasionar disfagia, sialorréia, feridas nos lábios e na língua e inchaço na face, além de edema na língua, palato mole, úvula, epiglote, úlceras na língua.

\subsection{Sansevieria trifasciata}

A espécie Sansevieria trifasciata também não apresentou diferença estatística para as concentrações testadas em nenhum dos métodos de ação avaliados. O controle positivo alcançou $100 \%$ de mortalidade e o controle negativo não ocasionou nenhuma morte tanto no método de ingestão quanto no método de contato.

Os métodos de ingestão e contato não apresentaram diferença significativa para as demais concentrações. A ordem decrescente de mortalidade foi de $70 \%>50 \%>60 \%$ para os dois métodos de ação. Individualmente as concentrações foram avaliadas, e a mortalidade das lagartas Spodoptera frugiperda não alterou entre os métodos. 
Tabela 7. Porcentagem de mortalidade de $S$. frugiperda após a aplicação das concentrações do extrato aquoso de $S$. trifasciata pelos métodos de ação de ingestão e contato.

\begin{tabular}{|c|c|c|}
\hline \multirow{3}{*}{ Concentrações } & \multicolumn{2}{|c|}{ Ação } \\
\hline & -----Mo & \\
\hline & \multicolumn{2}{|l|}{ Ingestão } \\
\hline $50 \%$ & $6,66 \mathrm{bA}$ & $3,61 \mathrm{bA}$ \\
\hline $60 \%$ & $1,66 \mathrm{bA}$ & $1,39 \mathrm{bA}$ \\
\hline $70 \%$ & $8,05 \mathrm{bA}$ & $9,16 \mathrm{bA}$ \\
\hline Controle positivo & $100 \mathrm{aA}$ & $100 \mathrm{aA}$ \\
\hline Controle negativo & $0 \mathrm{bA}$ & $0 \mathrm{bA}$ \\
\hline $\mathrm{CV}(\%)$ & \multicolumn{2}{|c|}{42,69} \\
\hline
\end{tabular}

Médias seguidas de mesma letra minúscula nas colunas e maiúsculas nas linhas não diferem entre si pelo teste de Scott knott ao nível de 5\% de probabilidade. Fonte: Autores.

Em relação aos dias de avaliação, verificou-se que o controle positivo teve todas suas lagartas mortas ainda no primeiro dia, mostrando seu poder inseticida. O controle negativo chegou ao último dia de avaliação com as lagartas vivas e foi estatisticamente igual à concentração de 60\% durante os quatro primeiros dias de avaliação, matando apenas 2 lagartas (Tabela $8)$.

A concentração de $70 \%$ teve uma crescente na taxa de mortalidade conforme os dias passavam e foi superior quando comparadas as outras durante todo o período de avaliação. No quinto dia a taxa de mortalidade desta era de 18 lagartas.

O primeiro e o segundo dia para a concentração de $50 \%$ foram iguais pelo teste de Scott Knott, a taxa de mortalidade deu um pequeno salto a partir do terceiro dia e manteve-se com 11 lagartas mortas até o quinto. Algo semelhante ocorreu com a concentração de $70 \%$, onde o primeiro e segundo dia havia 8 lagartas mortas, no terceiro e quarto dia a mortalidade foi de 13 e 15 lagartas mortas e no quinto dia haviam 18 lagartas mortas.

Tabela 8. Médias de mortalidade de lagartas $S$. frugiperda avaliadas por cinco dias após a aplicação do extrato de $S$. trifasciata nas concentrações testadas.

\begin{tabular}{|c|c|c|c|c|c|}
\hline \multirow{3}{*}{ Concentrações } & \multicolumn{5}{|c|}{ Dias } \\
\hline & & ---------- & ---------- & de $(\%)-----$ & -- \\
\hline & 1 & 2 & 3 & 4 & 5 \\
\hline $50 \%$ & $2,08 \mathrm{cB}$ & $3,47 \mathrm{cB}$ & $6,25 \mathrm{cA}$ & $6,25 \mathrm{cA}$ & $7,63 \mathrm{cA}$ \\
\hline $60 \%$ & $1,39 \mathrm{cA}$ & $1,39 \mathrm{dA}$ & $1,39 \mathrm{dA}$ & $1,39 \mathrm{dA}$ & $2,08 \mathrm{dA}$ \\
\hline $70 \%$ & $5,55 \mathrm{bC}$ & $5,55 \mathrm{bC}$ & $9,02 \mathrm{bB}$ & $10,41 \mathrm{bB}$ & $12,49 \mathrm{bA}$ \\
\hline Controle positivo & $100 \mathrm{aA}$ & $100 \mathrm{aA}$ & $100 \mathrm{aA}$ & $100 \mathrm{aA}$ & $100 \mathrm{aA}$ \\
\hline Controle negativo & $0 \mathrm{cA}$ & OdA & $0 \mathrm{dA}$ & OdA & $0 \mathrm{eA}$ \\
\hline $\mathrm{CV}(\%)$ & & & & & \\
\hline
\end{tabular}

Médias seguidas de mesma letra minúscula nas colunas e maiúsculas nas linhas não diferem entre si pelo teste de Scott knott ao nível de 5\% de probabilidade. Fonte: Autores.

Os métodos de ação diferiram estatisticamente apenas no primeiro e quinto dia de avaliação. No primeiro dia o método por contato foi superior e matou 57 lagartas $S$. frugiperda. No quinto dia a situação se inverteu e o método por ingestão foi superior acarretando a morte de 66 lagartas (Tabela 9).

A mortalidade das lagartas $S$. frugiperda foi estatisticamente igual para o método de ação por contato durante o período de avaliação. O método de ação por ingestão apresentou maior média no último dia, diferindo estatisticamente dos demais. 
Tabela 9. Avaliação da mortalidade de lagartas $S$. frugiperda nos métodos de ação ingestão e contato utilizados na aplicação do extrato de S. Trifasciata durante os cinco dias de avaliação.

\begin{tabular}{cccccc}
\hline & \multicolumn{5}{c}{ Dias } \\
Concentrações & 1 & -1 & 3 & 5 \\
& $21,11 \mathrm{bC}$ & $21,66 \mathrm{aC}$ & $23,61 \mathrm{aB}$ & $24,17 \mathrm{aB}$ & $25,83 \mathrm{aA}$ \\
Ingestão & $22,50 \mathrm{aA}$ & $22,50 \mathrm{aA}$ & $23,05 \mathrm{aA}$ & $23,03 \mathrm{aA}$ & $23,05 \mathrm{bA}$ \\
Contato & & \multicolumn{2}{c}{7,35} & \\
CV $(\%)$ & & & & \\
\hline
\end{tabular}

Médias seguidas de mesma letra minúscula nas colunas e maiúsculas nas linhas não diferem entre si pelo teste de Scott knott ao nível de 5\% de probabilidade. Fonte: Autores.

Na literatura científica não há relatos do uso de extrato de $S$. trifasciata no controle de insetos pragas. Haldar e colaboradores (2010) avaliaram o efeito do extrato hidroalcoólico do rizoma de Sansevieria roxburghiana para atividade antitumoral contra o carcinoma ascítico de Ehrlich em camundongos albinos e observaram redução significativa no volume tumoral, no volume globular e contagem de células viáveis além de aumentar o tempo de vida dos camundongos, provavelmente isto ocorre devido ao aumento dos mecanismos antioxidantes endógenos.

Segundo Sunilson (2009) o extrato etanólico e aquoso das folhas de S. trifasciata mostraram-se eficientes na limitação da dor além de inibir ambas as fases do teste de dor de formalina. O extrato etanólico também reduziu a febre induzida. Os autores realizaram uma triagem fotoquímica do extratos e descreveram a presença de alcalóides, flavonóides, saponinas, glicosídeos, terpenóides, taninos, proteínas e carboidratos.

\subsection{Tagetes erecta}

A espécie $T$. erecta não apresentou diferença significativa para nenhuma das concentrações avaliadas em ambos os métodos. Para o método de ingestão a mortalidade das lagartas S. frugiperda segue a ordem decrescente das concentrações $70 \%>60 \%>50 \%$, o método de ação por contato apresentou números mais expressivos para as concentrações de $60 \%$ e $70 \%$, onde morreram respectivamente 47 e 34 lagartas. O controle positivo causou mortalidade de 100\% das lagartas e o controle negativo não causou mortalidade das lagartas em nenhum dos métodos analisados (Tabela 10).

Tabela 10. Porcentagem de mortalidade de S. frugiperda após a aplicação das devidas concentrações do extrato aquoso de $T$. erecta pelos métodos de ação de ingestão e contato.

\begin{tabular}{|c|c|c|}
\hline \multirow{2}{*}{ Concentrações } & \multicolumn{2}{|c|}{ Ação } \\
\hline & Ingestão & Contato \\
\hline $50 \%$ & $7,22 \mathrm{bA}$ & $4,72 \mathrm{cA}$ \\
\hline $60 \%$ & $8,05 \mathrm{bA}$ & $12,22 \mathrm{bA}$ \\
\hline $70 \%$ & $9,44 \mathrm{bA}$ & $9,16 \mathrm{bA}$ \\
\hline Controle positivo & $100 \mathrm{aA}$ & $100 \mathrm{aA}$ \\
\hline Controle negativo & $0 \mathrm{cA}$ & $0 \mathrm{cA}$ \\
\hline $\mathrm{CV}(\%)$ & \multicolumn{2}{|c|}{31,14} \\
\hline
\end{tabular}

Médias seguidas de mesma letra minúscula nas colunas e maiúsculas nas linhas não diferem entre si pelo teste de Scott knott ao nível de 5\% de probabilidade. Fonte: Autores.

O controle positivo causou 100\% de mortalidade das lagartas já no primeiro dia de avaliação e diferiu das demais concentrações testadas durante todo o período de testes (Tabela 11).

No primeiro dia todas as concentrações foram consideradas iguais ao controle negativo pelo teste de Scott Knott, sendo que a concentração com maior número de lagartas $S$. frugiperda mortas foi a de $70 \%$ com apenas três. No segundo dia 
apenas as concentrações de $60 \%$ e $70 \%$ tiveram um aumento significativo nas mortes e foram estatisticamente diferentes das demais, chegando ao máximo de 12 lagartas mortas. No último dia de avaliação as concentrações citadas acima mantiveram a superioridade matando vinte e três lagartas na concentração de $60 \%$ e dezenove na de $70 \%$.

Assim como observado nas outras espécies vegetais avaliadas acima, a partir do terceiro dia o número de lagartas mortas aumenta substancialmente para praticamente todas as concentrações avaliadas.

Tabela 11. Médias de mortalidade de lagartas $S$. frugiperda avaliadas por cinco dias após a aplicação do extrato de $T$. erecta nas concentrações testadas.

\begin{tabular}{|c|c|c|c|c|c|}
\hline \multirow{3}{*}{ Concentrações } & \multicolumn{5}{|c|}{ Dias } \\
\hline & & ---------- & -----------M & e (\%)----- & \multirow[b]{2}{*}{5} \\
\hline & 1 & 2 & 3 & 4 & \\
\hline $50 \%$ & ObC & $3,47 \mathrm{cB}$ & $5,55 \mathrm{~dB}$ & $10,41 \mathrm{bA}$ & $10,41 \mathrm{cA}$ \\
\hline $60 \%$ & $1,38 \mathrm{bA}$ & $8,33 \mathrm{bB}$ & $13,88 \mathrm{bA}$ & $13,88 \mathrm{bA}$ & $15,97 \mathrm{bA}$ \\
\hline $70 \%$ & $2,08 \mathrm{bD}$ & $7,63 \mathrm{bC}$ & $9,72 \mathrm{cB}$ & $13,19 \mathrm{bA}$ & $13,88 \mathrm{bA}$ \\
\hline Controle positivo & $100 \mathrm{aA}$ & $100 \mathrm{aA}$ & $100 \mathrm{aA}$ & $100 \mathrm{aA}$ & $100 \mathrm{aA}$ \\
\hline Controle negativo & $0 \mathrm{bA}$ & $0 \mathrm{cA}$ & $0 \mathrm{eA}$ & $0 \mathrm{cA}$ & $0 \mathrm{dA}$ \\
\hline $\mathrm{CV}(\%)$ & \multicolumn{5}{|c|}{12.74} \\
\hline
\end{tabular}

Médias seguidas de mesma letra minúscula nas colunas e maiúsculas nas linhas não diferem entre si pelo teste de Scott knott ao nível de 5\% de probabilidade. Fonte: Autores.

Os métodos de ação ingestão e contato foram estatisticamente iguais durante todo o período de avaliação. Através da análise estatística foi possível observar que o método de ação por ingestão apresentou maior número de lagartas mortas no quarto e quinto dias, seguidos pelo terceiro dia e posteriormente pelo segundo e primeiro. Pelo método de ingestão os três últimos dias não diferiram entre si e apresentaram as maiores médias, seguidos pelo segundo dia, e posteriormente o primeiro com as menores médias (Tabela 12).

Tabela 12. Avaliação da mortalidade de lagartas $S$. frugiperda nos métodos de ação ingestão e contato utilizados na aplicação do extrato de T. erecta durante os cinco dias de avaliação.

\begin{tabular}{cccccc}
\hline & & \multicolumn{4}{c}{ Dias } \\
Concentrações & 1 & -23 & 3 & 5 \\
& $20,27 \mathrm{aD}$ & $23,61 \mathrm{aC}$ & $25,27 \mathrm{aB}$ & $27,78 \mathrm{aA}$ & $27,78 \mathrm{aA}$ \\
Ingestão & $21,11 \mathrm{aC}$ & $24,16 \mathrm{aB}$ & $23,39 \mathrm{aA}$ & $26,11 \mathrm{aA}$ & $28,33 \mathrm{bA}$ \\
Contato & & & & 12,74 \\
CV $(\%)$ & & & & \\
\hline
\end{tabular}

Médias seguidas de mesma letra minúscula nas colunas e maiúsculas nas linhas não diferem entre si pelo teste de Scott knott ao nível de 5\% de probabilidade. Fonte: Autores.

Restello e colaboradores (2009) encontraram resultados interessantes quanto à atividade inseticida após o uso do óleo essencial de Tagetes patula sobre adultos de Sitophilus zeamais. Nas maiores concentrações do óleo essencial 30 e $50 \mu \mathrm{L}$ a mortalidade dos insetos foi de $100 \%$. Na menor concentração utilizada de $5 \mu \mathrm{L}$ a mortalidade foi de $81 \%$, comprovando o efeito inseticida da espécie $T$. patula. Outras pesquisas obtiveram resultados semelhantes, porém usou-se extrato aplicado na forma de vapor.

De acordo com Signorini e colaboradores (2013) o extrato aquoso de Tagetes minuta foi eficaz na diminuição do consumo de folhas de batatada pela espécie Diabrotica speciosa nos testes com chance de escolha, sendo o resultado 
semelhante ao óleo de nim. Já nos ensaios utilizando o óleo essencial da flor e folhas de T. minuta, elevada taxa de mortalidade foi observada nos testes sem chance de escolha. O autor salienta a importância de novas pesquisas visto os resultados promissores apresentados na pesquisa basal.

\section{Conclusão}

As variações na taxa de mortalidade confirmam que os extratos oriundos das diferentes épocas de coletas possuem mortalidade diferenciada sobre essas lagartas. A coleta realizada no período de vazante é considerada um período inadequado para a coleta do material vegetal, devido a menor taxa de mortalidade. O mesmo pode ser concluído entre os modos de ação por ingestão apresentando numericamente maiores taxa de indivíduos mortos.

\section{Referências}

Altin, G. M. D., Sanli, A. M. D., Erdogan, B. A. M. D., Paksoy, M. M. D., Aydin, S. M. D. \& Altintoprak, N. M. D. (2013). Severe destruction of the upper respiratory structures after brief exposure to a Dieffenbachia plant. Journal of Craniofacial Surgery, 24(3), p. 245-7.

Barcelos, H. T., Hellwig, L., Medina, L. B., Trecha, C. O., Fipke, M. V. \& Afonso-Rosa, A. P. S. (2013). Monitoramento de Spodoptera frugiperda (J. E. Smith) (Lepidopitera: Noctuidae) em áreas de milho. Circular Técnica. Embrapa Clima Temperado.

Bueno, A. F., Panizzi, A. R., Côrrea-Ferreira, B. S., Hoffmann-Campo, C. B., Sosa-Gómez, D. R., Gazzoni, D. L., Hirose, E., Moscardi, F., Corso, I. C., Oliveira, L. J., Roggia, S. (2012). Histórico evolução do manejo integrado de pragas da soja no Brasil. In: Hoffmann-Campo, C. B., Côrrea-Ferreira, B. S., Moscardi, F. (Org.). Soja: manejo integrado de insetos e outros artrópodes-praga. Embrapa, 37-74.

Caldarelli, C. E. \& Bacchi, M. R. P. (2012). Fatores de influência no preço do milho no Brasil. Nova Econômia, 22(1), 141-64.

Carvalho, R. A., Omoto, C., Field, L. M., Williamsin, M. S. \& Bass, C. (2013). Investigating the molecular mechanisms of Organophosphate and Pyrethroid resistence in the Fall Armyworm Spodoptera frugiperda. Journal pone, 8(4), 1-10.

Gallo, D., Nakano, O., Silveira Neto, S., Carvalho, R. P. L., Batista, G. C., Berti Filho, E., Parra, J. R. P., Zucchi, R. A., Alves, S. B., Vendramin, J. D., Marchini, L. C., Lopes, J. R. S., Omoto, C. (2002). Entomologia agrícola. Piracicaba: FEALQ.

Guedes, J.C., Arnemann, J.A., Bigolin, M., Perini, C. R., Cagliari, D., Stacke, R. F. (2012). Revisão necessária. Revista Cultivar,14 (1), $22-24$.

Ferreira, D. F. (2011). Sisvar: a computer statistical analysis system. Ciência e Agrotecnologia, 35(6), 1039-42.

Haldar, P. K., Kar, B., Bala, A., Bhattacharya, S. \& Mazumder, U. K. (2010). Antitumor activity of Sansevieria roxburghiana rhizome against Ehrlich ascites carcinoma in mice. Pharmaceutical Biology, 48(12), 1337-43.

Loretti, A. P., Silva Ilha, M. R. \& Ribeiro, R. E. (2003). Accidental fatal poisoning of a dog by Dieffenbachia picta (Dumb cane). Veterinary and Human Toxicology, 45(5), 233-9.

Mazzoneto, F., Coradini, F., Corbani, R. Z. \& Dalri, A. B. (2013). Ação de inseticidas botânicos sobre a preferência alimentar e sobre posturas de Spodoptera frugiperda (J. E. SmithP) (Lepdoptera: Noctuidae) em Milho. Entomo Brasilis, 6(1), 34-8.

Parra, J. R. P. (2001). Técnicas de criação de insetos para programas de controle biológico. FEALQ.

Resende, D. C., Mendes, S.M., Waquil, J.M., Duarte, J. O. \& Santos, F.A. (2014). Adoção da área de refúgio e manejo de resistência de insetos em milho Bt. Revista de Política Agrícola, 1(23), 119-28.

Restello, R. M., Menegatt, C. \& Mossi, A. J. (2009). Efeito do óleo essencial de Tagetes pátula L. (Asteraceae) sobre Sitophilos zeamais Motschulsky (Coleoptera, curculionidae). Revista Brasileira de Entomologia, 53(2), 304-7.

Signorini, C. B., Trecha, C. O., Schiedeck, G., Mauch. C. R. \& Lovatto, P. B. (2013). Atividade do óleo essencial e extrato aquoso de Tagetes minuta (Asteraceae) sobre o consumo alimentar de Diabrotica speciosa (Germar, 1824) (Coleoptera: Chrysomelidae) em batata, sob condições de laboratório. Cadernos de Agroecologia, 8(2), 1-5.

Silva, E. N., Lima Junior, A. F., Brito, G. S., Silva, M. C., Costa, F. R. \& Oliveira, I. P. (2015). Controle do Tribolium castaneum em arroz armazenado com diferentes extratos vegetais. Revista Faculdade Montes Belos 8(5), 34-139, 2015.

Simões, C. M.O., Schenkel, E. P., Mello, J. C. P., Mentz, L. A. \& Petrovick, P. R. (2016). Farmacognosia: do produto natural ao medicamento. Artmed.

Sunilson, A. J., Varatharajan, R., Thomas, J., James, J. \& Muthappan, M. (2009). Analgesic and antipyretic effects of Sansevieria trifasciata leaves. African Journal Traditional, 6(4), 529-33.

Yeasmin, D., Swarna, R. J., Nasrin, S., Parvez, S. \& Alam, M. F. (2016). Phytochemical analysis and antioxidant activity of three flower colours Chrysanthemum morifolium Ramat. International Journal of Biological Science, 9(2), 69-77.

Zanon, A. J., Winck, J. E. M., Streck, N. A., Rocha, T. S. M, Cera, J. C., Richter, G.L., Lago, I., Santos, P. M., Maciel, L. R., Guedes, J. V. C., Marchesan, E. (2015). Desenvolvimento de cultivares de soja em função do grupo de maturação e tipo de crescimento em terras altas e terras baixas. Bragantia, Campinas, 74(4), 400- 411 